\title{
Predictive models for arteriovenous fistula maturation.
}

DOI:

10.5301/jva. 5000500

\section{Document Version}

Accepted author manuscript

Link to publication record in Manchester Research Explorer

\section{Citation for published version (APA):}

Al Shakarchi, J., McGrogan, D., Van Der Veer, S., Sperrin, M., \& Inston, N. (2016). Predictive models for arteriovenous fistula maturation. The journal of vascular access. https://doi.org/10.5301/jva.5000500

\section{Published in:}

The journal of vascular access

\section{Citing this paper}

Please note that where the full-text provided on Manchester Research Explorer is the Author Accepted Manuscript or Proof version this may differ from the final Published version. If citing, it is advised that you check and use the publisher's definitive version.

\section{General rights}

Copyright and moral rights for the publications made accessible in the Research Explorer are retained by the authors and/or other copyright owners and it is a condition of accessing publications that users recognise and abide by the legal requirements associated with these rights.

\section{Takedown policy}

If you believe that this document breaches copyright please refer to the University of Manchester's Takedown Procedures [http://man.ac.uk/04Y6Bo] or contact uml.scholarlycommunications@manchester.ac.uk providing relevant details, so we can investigate your claim.

\section{OPEN ACCESS}




\section{Predictive Models for Arteriovenous}

\section{Fistula Maturation}

Julien Al Shakarchi ${ }^{1}$

Damian McGrogan ${ }^{1}$

Sabine Van der Veer ${ }^{2}$

Matthew Sperrin²

Nicholas Inston ${ }^{1}$

1 Department of Renal Surgery, University Hospital Birmingham, UK.

2 University of Manchester, UK

Correspondence address:

Julien Al Shakarchi

Department of Renal Surgery

University Hospital Birmingham

Birmingham, UK

j.alshakarchi@nhs.net

Keywords: Arteriovenous fistula, haemodialysis, Model, Maturation, Patency 


\section{ABSTRACT}

Haemodialysis (HD) is a lifeline therapy for patients with end stage renal disease (ESRD). A critical factor in the survival of renal dialysis patients is the surgical creation of vascular access and international guidelines recommend arteriovenous fistulas (AVF) as the gold standard of vascular access for haemodialysis. Despite this, AVFs have been associated with high failure rates. Although risk factors for AVF failure have been identified, their utility for predicting AVF failure through predictive models remains unclear. The objectives of this review are to systematically and critically assess the methodology and reporting of studies developing prognostic predictive models for AVF outcomes and assess them for suitability in clinical practice.

Electronic databases were searched for studies reporting prognostic predictive models for AVF outcomes. Dual review was conducted to identify studies that reported on the development or validation of a model constructed to predict AVF outcome following creation. Data was extracted on study characteristics, risk predictors, statistical methodology, type of model as well as validation process. We included 4 different studies reporting five different predictive models. Parameters identified that were common to all scoring system were age and cardiovascular disease.

This review has found a small number of predictive models in vascular access. The disparity between each study limits the development of a unified predictive model.

\section{INTRODUCTION}


Predictive models, both diagnostic and prognostic, are tools that combine multiple predictors to obtain a risk or probability. They are becoming increasingly described in the medical literature and used in clinical practice. These models have considerable potential to contribute to the decision-making process regarding the management of a patient. Typically, they combine several clinical, investigational or patient related measures to calculate the likelihood of an outcome.

Haemodialysis (HD) is a life preserving therapy for patients with end stage renal disease (ESRD). It is estimated that over 1.5 million patients receive regular HD treatment worldwide with the number growing at a rate of around $7 \%$ (1). A critical factor in the survival of renal dialysis patients is the surgical creation of vascular access and international guidelines recommend arteriovenous fistulas (AVF) as the gold standard of vascular access for HD. $(2,3)$ Unfortunately, AVFs have been associated with high failure rates, being reported at 30 to $50 \%$ predominately due to aggressive pathological process termed venous intimal hyperplasia $(\mathrm{VIH}) \cdot(4,5)$ Numerous factors have been described as having an effect on the success rate and therefore a prognostic predictive model would be extremely important in planning in clinical practice for example guiding decisions on the site of the AVF.(6) Existing reviews of prediction models in other diseases have shown that model design is critical and many models are poorly developed with weaknesses in their methodology, validation and reporting.(7)

The objectives of our review are to systematically and critically assess the methodology and reporting of studies developing prognostic predictive models for AVF outcomes and assess them for suitability in clinical practice.

\section{METHOD}


Searches of Pubmed central, Ovid Medline and Ovid Embase were performed using the combination of the following search terms: haemodialysis, haemofiltration or renal failure with vascular access, arteriovenous fistula or arteriovenous shunt in addition to the Haynes tool for finding prognostic prediction models to identify suitable published articles. In addition, the references cited in selected articles were reviewed for any further relevant available studies as well as our personal reference list. Articles were not restricted to any language and searches were carried out up to $31^{\text {st }}$ May 2015. Grey literature was not searched or included. The systematic review was performed in accordance with the PRISMA (Preferred Reporting Items for Systematic Reviews and Meta-Analyses) guidelines.(8)

Articles were included if they aimed to develop a multivariable prognostic predictive model for AVF maturation or patency outcomes. Articles were excluded if they did not develop a new model or the outcome was different from the inclusion criteria.

Two reviewers (J.A. and D.M.) independently identified articles and screened them for inclusion. Disagreements were solved by consensus between authors. Where this was not possible, a 3rd opinion (N.I) was sought. Eligible articles were used to develop a potential prognostic assessment tool for predicting patency of arteriovenous fistula at 1-year. Studies that assess causal effect of a predictor(s) without modelling were excluded.

From each study, we extracted data on study design, population, outcome definition, setting, demographics, the number of patients included, the number of variables tested as predictors, model development and evaluation, the type of statistical model, using a data extraction sheet. Each study underwent assessment using the TRIPOD statement.(9)

\section{RESULTS}


A total of 1378 articles and abstracts were identified using our search strategy. After screening the contents of the abstract, 16 full text articles underwent assessment for eligibility and quality inspection of methodology. (Figure 1) Following the assessment, 4 articles were found to be eligible for the review. (Table 1) One paper proposed two different models and therefore a total of five models have been included in our study. Three models were developed using North American data from Canada (10) and United States (11) and the other two models were European from the United Kingdom $(12,13)$. Of note, the two British papers only focused on one type of AVF each (radiocephalic \& snuff box).(12,13)

\section{Number of abstracts identified in search strategy: 1378}

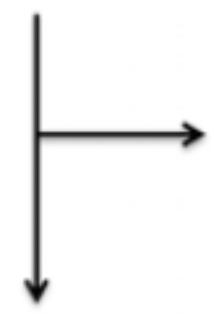

Articles excluded:

-Wrong topic 1362

\section{Number of full text articles assessed for inclusion in the study: 16}

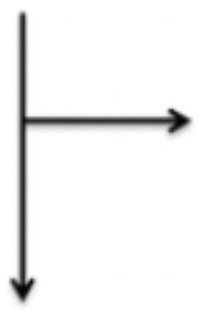

Articles excluded:

- Wrong model topic 4

- Individual predictors/no successful modeling 5

- Wrong topic 3

Final number of included studies in the review: 4

Figure 1 Flowsheet of results of search strategy with inclusion and exclusions following searches and screening. 
The number of participants included in the development of the prediction models was clearly reported in all four studies, ranging from 218 to 422 patients. The prognostic predictive models included a median of five risk predictors. The most commonly identified risk predictors included age, venous diameter and CVD. Three models used multivariable regression model whilst the other two models used a series of separate univariable cox regression analyses. All studies clearly identified the type of statistical method that they used to derive the prediction model, two were derived using a Cox proportional hazards model $(12,13)$ and three models used logistic regression $(10,11)$.

All five studies claimed to have carried out some form of evaluation of the prediction model. Three models $(10,11)(60 \%)$ conducted an internal validation of the prediction model with bootstrapping, with one of them also using an internal cross validation and external validation (11), In our opinion two studies did not sufficiently assess their models to validate them.(12,13)

Three studies $(11,12,13)(60 \%)$ derived simplified scoring systems from the risk prediction models. One study (11) derived a simple points system by rounding odds ratios to the nearest integer, whereby the resulting score would be a simple summation of the integers. One study (12) derived a simple scoring system by giving an integer of 1 for all significant variables however they did not actually use the hazard ratios from the cox model. The second study (13) used a similar simple method, however decided to give two significant variables an integer of 2 due to their higher hazards ratio. Parameters identified that were common to all scoring system were age and CVD (cardiovascular disease). Recent studies have confirmed both age and CVD as a risk factor in VA outcomes which supports both as potential prognostic markers.(14) Previous access was identified as a risk factor in two studies and specifically contralateral previous access. Venous diameter, a major factor in access planning was 
only noted in three models although studies assessing outcome using vein size less than a pre-defined threshold (e.g. $<2 \mathrm{~mm}$ cephalic vein at wrist) show a strong correlation with failure.(6)

Dialysis dependency and BP was noted in two studies. Whilst studies subdividing patients into pre-dialysis and post dialysis AVF formation show better outcomes for the former this may be confounded by multiple factors such as previous access attempts, central venous catheters, uraemia and overall clinical co-mordidity.(6)

In access naïve patients AVF outcome was no different than in patients who had already started dialysis although in patients where access was created on the ipsilateral side as a previous CVC had worse outcomes. This is consistent with previous access being a parameter.

Ethnicity which has previously shown to affect outcome was only used in one study may reflect the low level of ethnic diversity in the studies rather than a true reflection of ethnicity as a risk.(11)

Pre -existing disease such as diabetes was only a risk in one model although other markers of arterial disease (previous cerebrovascular accident /previous lower limb angioplasty/peripheral vascular disease) were used. The contribution of arterial factors to AVF outcome is poorly defined and more accurate measures may be required to enable inclusion in prognostic models.

One model used absent intra-operative thrill as a strong, but not unexpected marker of negative outcome.

\section{DISCUSSION}

Haemodialysis is a lifeline for end stage renal failure patients with vascular access 
being a major component of survival. Arteriovenous fistulas have been described as the gold standard due to its potential long-term patency, decreased rate of complications such as infection and overall survival benefit.(15) Despite this a major limitation of AVFs is the need for the vein to mature to a size large enough to be needled for haemodialysis. A number of factors have been associated with failure of maturation and this has been described widely in the current literature.(6) These include both patient and surgical variables.

In the general medical literature, scoring systems and predictive models have been widely recognized as useful tools in stratifying patients and predicting outcomes in cohorts of patients. In vascular access, the ability to predict successful maturation, or high risk of failure to mature may allow tailoring of clinical practice to individual patients and allow better planning of procedure and improved success. In common with many areas of vascular access where the current literature has little evidence there is a lack of available data on predictive models and this review could only find four eligible studies with a total of five models being described. This is a limitation to this review, although it does highlight a key area for future research. Only one paper was found to attempt to validate the available models, it would suggest that these are not widely used in clinical practice. (16) The lack of demonstration of validation and performance evaluation of these models on new populations makes it impossible to recommend these models. Further testing and validation by a different group of investigators in different patient cohorts is necessary. More advanced statistical approaches such as boot strapping to internally validate the predictive model may be used.

A weakness of comparing these models is the heterogeneity of outcomes that were used in the available models in particular AVF maturation, AVF non-maturation or AVF patency. $(10,11,12,13)$ This is a typical problem in studies of vascular access as 
different and often non-standardized outcomes are commonly described in different studies making comparison challenging and recommendations for standard outcome measures is mandated.(17)

The number of patients involved in the modelling process in the identified studies ( $n=218$ to 422 ) compares poorly to available models on other topics such as end stage renal failure where numerous models used over 5000 patients.(7) Compared to models used in other topics, those available to this review use few variables. The results of haemodialysis fistula maturation study (18) will hopefully yield more data for predictive modelling with a higher number of patients and potentially more predictive variables.

In conclusion this review has found a small number of predictive models in vascular access. The disparity between each study limits the development of a unified predictive model and therefore we recommend more research is required in this field. The utility of an accurate well-designed predictive model, which could be applicable to a clinical setting, would provide benefit in the planning and tailoring of vascular access for haemodialysis.

\section{Conflicts of interest}

None declared

\section{Acknowledgements}


SV is a fellow of the methods support team of European Renal Best Practice, supported by a grant of the European Renal Association- European Dialysis Transplantation Association. 


\section{References}

1. Grassmann A, Gioberge S, Moeller S, Brown G. ESRD patients in 2004: global overview of patient numbers, treatment modalities and associated trends. Nephrol Dial Transplat. 2005 20(12): 2587-2593

2. Vascular Access 2006 Work Group Clinical practice guidelines for vascular access. Am J Kidney Dis. 2006 48:S176-S247

3. Tordoir et al. EBPG on Vascular Access. Nephrol. Dial. Transplant. 2007 22:ii88-ii117

4. Nikam M, Popuri RK, Taylor U, Farquharson F, Mitra S, Chalmers N. Arteriovenous fistula failure: is there a role for accessory draining vein embolization. J Vasc Access. 2012 13(4): 498-503

5. Al-Jaishi AA, Oliver MJ, Thomas SM, Lok CE, Zhang JC, Garg AX, Kosa SD, Quinn RR, Moist LM. Patency rates of the arteriovenous fistula for hemodialysis: a systematic review and meta-analysis. Am J Kidney Dis. 2014 63(3):464-78

6. Smith GE, Gohil R, Chetter IC. Factors affecting the patency of arteriovenous fistulas for dialysis access. J Vasc Surg. 2012 55(3):849-5

7. Collins GS, Omar O, Shanyinde M, Yu LM. A systematic review finds prediction models for chronic kidney disease were poorly reported and often developed using inappropriate methods. J Clin Epidemiol. 2013 66:268-277

8. Moher D, Liberati A, Tetzlaff J, Altman DG, The PRISMA Group. Preferred reporting items for systematic reviews and meta-analyses: the prisma statement. PLoS Med. 2009 6:e1000097

9. Collins GS, Reitsma JB, Altman DG, Moons KGM. Transparent reporting of a multivariable prediction model for individual prognosis or diagnosis (TRIPOD): 
The tripod statement. Ann Intern Med. 2015 162:55-63

10.Feldman HI, Joffe M, Rosas SE, Burns JE, Knauss J, Brayman K. Predictors of successful arteriovenous fistula maturation. American Journal of Kidney Diseases. 2003 42(5):1000-1012

11.Lok CE, Allon M, Moist L, Oliver MJ, Shah H, Zimmerman D. Risk Equation Determining Unsuccessful Cannulation Events and Failure to Maturation in Arteriovenous Fistulas (REDUCE FTM I). J Am Soc Nephrol 2006 17:32043212

12. Twine CP, Haidermota M, Woolgar JD, Gibbons CP, Davies CG. A Scoring System (DISTAL) for Predicting Failure of Snuffbox Arteriovenous Fistulas. Eur J Vasc Endovasc Surg 2012 44:88-91

13. Bosanquet DC, Rubasingham J, Imam M, Woolgar JD, Davies CG. Predicting outcomes in native AV forearm radio-cephalic fistulae; the CAVEA2T2 scoring system. J Vasc Access 2015 16(1): 19-25

14. McGrogan D, Al Shakarchi J et al. Arteriovenous Fistula Outcomes in the Elderly. J Vasc Surg. 2015 In press

15. Dhingra RK, Young EW, Hulbert-Shearon TE, Leavey SF, Port FK. Type of vascular access and mortality in U.S. hemodialysis patients. Kidney Int. 2001 60(4):1443-51.

16. Lilly MP, Lynch JR, Wish JB, Huff ED, Chen SC, Armistead NC, McClellan WM Prevalence of arteriovenous fistulas in incident hemodialysis patients: correlation with patient factors that may be associated with maturation failure. Am J Kidney Dis. 2012 59(4):541-9

17. Sidawy A, Gray R, Besarab A, Henry M, Ascher E, Silva M, Miller A, Scher L, Trerotola S, et al. Recommended Standards for Reports Dealing with 
Arteriovenous Hemodialysis Accesses. J Vasc Surg 2002; 35:603-610.

18. Dember LM, Imrey PB et al. Objectives and design of the hemodialysis fistula maturation study. Am J Kidney Dis. 2014 63(1):104-12 
Tables

Table 1

\begin{tabular}{|c|c|c|c|c|}
\hline $\begin{array}{c}\text { TRIPOD statement } \\
\text { checklist }\end{array}$ & Feldman $^{10}$ & Lok $^{11}$ & Twine $^{12}$ & Bosanquet $^{13}$ \\
\hline Title & & $\bar{x}$ & $\bar{x}$ & $\bar{x}$ \\
\hline Abstract & $\mathrm{X}$ & 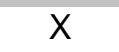 & $\mathrm{X}$ & $x$ \\
\hline Background & & $x$ & $x$ & $x$ \\
\hline Source of data & $\mathrm{X}$ & $\mathrm{X}$ & $\mathrm{X}$ & $\mathrm{X}$ \\
\hline Participants & $\mathrm{x}$ & $\mathrm{X}$ & $\mathrm{X}$ & $x$ \\
\hline Outcome & $\mathrm{X}$ & $\mathrm{X}$ & & $\mathrm{X}$ \\
\hline Predictors & $\mathrm{x}$ & $x$ & $x$ & $x$ \\
\hline Sample size & $x$ & $x$ & $\mathrm{X}$ & $x$ \\
\hline Missing data & $x$ & $x$ & $x$ & \\
\hline Statistical analysis & $\mathrm{X}$ & $x$ & $x$ & $x$ \\
\hline Risk groups & & $x$ & & \\
\hline Development/validation & $x$ & $x$ & & \\
\hline Participitants & $x$ & $x$ & & \\
\hline Model development & $x$ & $\mathrm{x}$ & $x$ & $\mathrm{x}$ \\
\hline Model specification & $\mathrm{x}$ & $\mathrm{X}$ & $\mathrm{X}$ & $\mathrm{X}$ \\
\hline Model performance & $\mathrm{x}$ & $\mathrm{x}$ & & \\
\hline \multicolumn{5}{|l|}{ Model updating } \\
\hline Limitations & $\mathrm{x}$ & $\mathrm{x}$ & & $\mathrm{x}$ \\
\hline Interpretation & $\mathrm{x}$ & $\mathrm{x}$ & $x$ & $x$ \\
\hline Implications & $\mathrm{X}$ & $X$ & $X$ & $x$ \\
\hline $\begin{array}{l}\text { Supplementary } \\
\text { information }\end{array}$ & & & & $x$ \\
\hline Funding & $X$ & $X$ & $X$ & $x$ \\
\hline
\end{tabular}


Table 2

\begin{tabular}{|c|c|c|c|c|c|c|c|c|c|}
\hline Study & $\begin{array}{l}\text { Year of } \\
\text { publicati } \\
\text { on }\end{array}$ & Country & Design & $\begin{array}{l}\text { Study } \\
\text { population }\end{array}$ & Outcome & Sample size & Predictors in the model & Method of validation & Type of model \\
\hline $\begin{array}{l}\text { Feldman } \\
\text { (10) }\end{array}$ & 2003 & US & $\begin{array}{l}\text { Prospectiv } \\
\text { e cohort } \\
\text { study }\end{array}$ & $\begin{array}{l}\text { ESRF patients } \\
>18\end{array}$ & $\begin{array}{l}\text { AVF maturation } \\
\text { (yes/no) }\end{array}$ & 348 & $\begin{array}{l}\text { Age, CVD, Previous access, } \\
\text { BP, dialysis dependent, } \\
\text { Heparin use, Vein diameter }\end{array}$ & Internal: Bootstrap & $\begin{array}{l}\text { Multivariable logistic regression model } \\
\text { / Generalised estimating equations }\end{array}$ \\
\hline $\begin{array}{l}\text { Feldman } \\
\text { (10) }\end{array}$ & 2003 & us & $\begin{array}{l}\text { Prospectiv } \\
\text { e cohort } \\
\text { study }\end{array}$ & $\begin{array}{l}\text { ESRF patients } \\
>18\end{array}$ & $\begin{array}{l}\text { AVF maturation } \\
\text { (yes/no) }\end{array}$ & 348 & $\begin{array}{l}\text { Age, CVD, Previous access, } \\
\text { BP, dialysis dependent }\end{array}$ & Internal: Bootstrap & $\begin{array}{l}\text { Multivariable logistic regression model } \\
\text { / Generalised estimating equations }\end{array}$ \\
\hline Lok (11) & 2006 & Canada & $\begin{array}{l}\text { Prospectiv } \\
\text { e cohort } \\
\text { study }\end{array}$ & $\begin{array}{l}\text { ESRF } \\
\text { patients } \\
>18\end{array}$ & $\begin{array}{l}\text { AVF non maturation } \\
\text { (yes/no) }\end{array}$ & 422 & Age, PVD, CVD, Ethnicity & $\begin{array}{l}\text { Internal: cross validation and } \\
\text { bootstrapping and External }\end{array}$ & Multivariable logistic regression model \\
\hline Twine (12) & 2012 & UK & $\begin{array}{l}\text { Retrospect } \\
\text { ive cohort } \\
\text { study }\end{array}$ & $\begin{array}{l}\text { ESRF } \\
\text { Patients } \\
>18 \text { Snuffbox } \\
\text { fistulas }\end{array}$ & $\begin{array}{l}\text { Time to Patency } \\
\text { failure (yes/no) }\end{array}$ & 218 & $\begin{array}{l}\text { Age, second contralateral } \\
\text { procedure, venous diameter, } \\
\text { CVD, CVA, Diabetes }\end{array}$ & None & $\begin{array}{l}\text { A series of separate univariable Cox's } \\
\text { proportional hazards regression }\end{array}$ \\
\hline $\begin{array}{l}\text { Bosanque } \\
\mathrm{t}(13)\end{array}$ & 2015 & UK & $\begin{array}{l}\text { Retrospect } \\
\text { ive cohort } \\
\text { study }\end{array}$ & $\begin{array}{l}\text { ESRF } \\
\text { Patients } \\
>18 \\
\text { Forearm fistulae }\end{array}$ & $\begin{array}{l}\text { Time to Patency } \\
\text { failure }\end{array}$ & 276 & $\begin{array}{l}\text { Central venous access, Age, } \\
\text { Venous diameter, previous } \\
\text { lower limb angioplasty, Absent } \\
\text { intra-operative thrill }\end{array}$ & None & $\begin{array}{l}\text { A series of separate univariable Cox's } \\
\text { proportional hazards regression }\end{array}$ \\
\hline
\end{tabular}

